\title{
Friendship quality as a moderator between perception of interparental conflicts and maladjustment in adolescence
}

\author{
Helle Larsen, Susan J.T. Branje, Inge van der Valk, and Wim H.J. Meeus \\ Research Centre Adolescent Development, Utrecht University, The Netherlands
}

\begin{abstract}
The aim of this study was to longitudinally examine the moderating role of friendship quality in the association between adolescent perception of interparental conflicts and maladjustment. Participants were 1294 adolescents enrolled in the Dutch CONAMORE 2001-2006 study ( $M_{\text {age }}=13.6$ years). AMOS multigroup analyses were utilized. Results show that low friendship quality is a risk factor for both boys and girls, aggravating the effect of interparental conflicts on anxiety, whereas for aggression this was only the case for boys. No convincing support was found for high friendship quality's protective function against the effect of perceived interparental conflict on maladjustment. These findings show the substantial importance of not being in a low quality friendship when adolescents perceive interparental conflicts.
\end{abstract}

Keywords: adolescence; aggression; anxiety; friendship quality; interparental conflicts

Years of research have established a link between interparental conflicts and maladjustment in children and adolescents (Cummings \& Davies, 2002; Cummings, Goeke-Morey, \& Papp, 2003; Davies, Dumenci, \& Windle, 1999; Davies, Sturge-Apple, Winter, Cummings, \& Farrell, 2006; van der Valk, 2004). Unfortunately, the prevalence of offspring's exposure to interparental conflicts is high (Margolin, Oliver, \& Medina, 2001). Nonetheless, many offspring are well-adjusted in spite of living under circumstances with interparental conflicts. The main goal of the current study is to examine the moderating role of friendship quality in the relation between adolescents' perception of interparental conflicts and anxiety and aggression, respectively. We are interested in two possible moderating roles of friendship quality: (1) adolescent high friendship quality as buffering the possibly adverse effects of adolescent perception of interparental conflicts, and (2) adolescent low friendship quality as a risk factor, aggravating the possible adverse effect of adolescent perception of interparental conflicts.

\section{Interparental conflicts and adolescent adjustment}

Interparental conflicts have been found to have both direct and indirect effects (e.g., via the effect of marital discord on parental functioning) on child functioning from infancy through adolescence (e.g., Buehler, Krishnakumar, Stone, Anthony, Pemberton, \& Gerard, 1998; Gable, Belsky, \& Crnic, 1992). Empirical studies have shown that children and adolescents who grow up in harmonious family environments have less psychosocial problems than children and adolescents growing up in environments with marital distress. Adolescents from disharmonious families, for example with divorced or feuding parents, show lower levels of well-being (Hetherington
\& Stanley-Hagan, 1999) and higher levels of both internalizing and externalizing problems (Amato \& Keith, 1991; Buehler, Anthony, Krishnakumar, Stone, Gerard, \& Pemberton, 1997; Buehler et al., 1998; Hetherington, 1999; Johnson, LaVoie, \& Mahoney, 2001). Recently, Cummings and colleagues (2006) found that the association between interparental conflicts and child adjustment increases as children move into adolescence. This finding indicates that adolescence may be a particularly salient period, perhaps because of the increasing effects of children's own reactions upon interparental conflicts. It is thus important to investigate these relations in adolescence.

A broad span of literature and empirical research indicates that offspring's perception of conflicts is important to consider when examining the association between interparental conflict and child adjustment (Cummings, Davies, \& Simpson, 1994; Gerard, Buehler, Franck, \& Anderson, 2005; Harold, Fincham, Osborne, \& Conger, 1997). Children and adolescents that report higher levels of perceived conflict intensity and frequency show higher levels of both internalizing and externalizing problems (e.g., Cummings et al., 2003; Grych \& Fincham, 1993; Grych, Seid, \& Fincham, 1992; Laursen, 1993). Therefore, the current study focuses upon adolescents' perceptions of interparental conflicts, because we assume that the conflicts are only associated with adjustment to the extent that they are perceived by the adolescent (Kitzmann \& Cohen, 2003).

\section{Interparental conflicts and the moderating role of friendship quality}

Nowadays, it is generally accepted that the interactive influence of family and peer factors on child and adolescent adjustment is crucial (Bronfenbrenner \& Morris, 1998; Cummings 
\& Davies, 2002; Hartup, 1996; Kim, Hetherington, \& Reiss, 1999). It is suggested that peer relations can moderate the influence of parental marital problems on child adjustment (e.g., Davies \& Windle, 2001; Hetherington \& Stanley-Hagan, 1999; Wasserstein \& La Creca, 1996). Friendships are especially important in adolescence. First, not only having friends, but also the quality of friendships, is related with child and adolescent well-being (Hartup, 1996), psychosocial health, and adaptive development (Bagwell, Bender, Andreassi, Kinoshita, Montarello, \& Muller, 2005; Hartup \& Stevens, 1997; for a review see Rubin, Bukowski, \& Parker, 1998). Second, increased affiliation and reliance on peers across adolescence, in addition to decreased dependency on parents, is often a part of normative development (Buist, Deković, Meeus, \& van Aken, 2002; Steinberg \& Silverberg, 1986). An increasing amount of time is spent with friends and the nature of friendships changes to become more intimate (Shulman, Laursen, Kalman, \& Karpovsky, 1997). For these reasons, examining the role of friendship in adolescence may be fundamental to understanding the links between perceived interparental conflicts and maladjustment.

On the one hand, friendship quality may be a protective factor when adolescents have to cope with life stressors such as interparental discord. Friendships offer adolescents opportunities to diminish the effect of family conflicts by disclosure, support, and security within the friendship relation (Criss, Pettit, Bates, Dodge, \& Lapp, 2002). To our knowledge, only one study has examined the moderating effect of friendship quality on the link between perceived interparental conflicts and adjustment. This study revealed evidence for a moderating effect of friendship support in childhood (Wasserstein \& La Creca, 1996). Children who perceived their parents' marriage as more conflictual exhibited higher levels of behavioral problems only when they also experience low levels of support from close friends. Other studies have found a buffering effect of friendship on relations between other family measures and child adjustment. For example, during adolescence, a positive friendship has been found to buffer the negative effects of a bad family environment, where support is unavailable, as well as the effects of negative parenting on child well-being (Gauze, Bukowski, Aquan-Assee, \& Sippola, 1996; Lansford, Criss, Pettit, Dodge, \& Bates, 2003). Gauze and colleagues (1996) found that the association between family measures and maladjustment was weaker for children with a best friend or children who perceived their friendships as being of relatively higher quality. Lansford and colleagues (2003) found moderating effects of friendship quality, peer group affiliation, and peer antisocial behavior on the relation between negative parenting and adolescent externalizing behavior. Friendship quality and peer group affiliation served as protective factors for adolescents exposed to unilateral parental decision-making. These findings indicate that friendships may function as protective factors that diminish the effects of stressful family experiences during adolescence.

On the other hand, if adolescents do not have good-quality friendships when dealing with feuding parents, the adolescent may be at higher risk of maladjustment. Lansford and colleagues (2003) also found evidence for friendship as a risk factor. For adolescents with low friendship quality and affiliation, unilateral parental decision-making was significantly associated with subsequent externalizing behavior. It is thus likely that the moderating effect of low friendship quality and peer antisocial behavior is an intensification of at-risk adolescents' problems. Moreover, interparental conflicts may be related to adolescent disengagement from the family and fewer shared family activities (Hetherington, 1999). Thus, the adolescent may spend more unsupervised time with peers and may be more influenced by antisocial behavior. This could also lead to an increase in, especially, externalizing behavior (Lansford et al., 2003).

\section{The present study}

Aforementioned research indicates that the quality of friendships might buffer or strengthen the negative effects of interparental conflict perception on adolescent psychosocial adjustment. However, this moderating role of friendships has only been examined in children, with internalizing and externalizing behaviors taken together (Wasserstein \& La Creca, 1996), and has never been studied longitudinally. The current study will examine whether high quality friendships buffer the association between adolescents' perceptions of interparental conflict and anxiety and aggression, respectively, two years later. Additionally, we will investigate whether low friendship quality is a risk factor for adolescent adjustment. By comparing adolescents both with high friendship quality and adolescents with low friendship quality to a neutral reference group of adolescents with normative friendship quality, we can examine whether both a buffering effect and a risk factor effect are present. We use the term "normative" friendship quality, to imply an average level of friendship quality.

Through investigating the relation between perceived interparental conflicts and both internalizing and externalizing problems separately, we are able to examine the consequences of perceived interparental conflicts for adolescents. By assessing a wider range of adjustment indices we can determine whether some outcomes are more closely related to exposure to interparental conflicts than are others (Grych \& Fincham, 1990). We will utilize longitudinal data to address our research questions so that concurrent relations, relations over time, and correlated change (Neyer \& Asendorpf, 2001) can be simultaneously considered.

Three main issues will be examined. The first research question is whether there is a relation between adolescents' perceptions of interparental conflicts and anxiety and aggression, respectively. It is hypothesized that adolescent perception of interparental conflicts will be positively associated with anxiety and aggression. Second, we will examine whether the quality of adolescent friendships can function as a moderator in the relation between perceived interparental conflict and anxiety and aggression. It is expected that a high friendship quality will have a buffering effect against adolescent problems resulting from parental discord, whereas a low friendship quality is expected to be a risk factor for problem behavior following interparental conflict. Third, we will explore whether there are differences between boys and girls in the hypothesized moderating effect of friendship quality. Girls' friendships are often characterized by higher intimacy and support and thus friendship quality may be a more important moderator for girls compared to boys (Crawford, Cohen, Midlarsky, \& Brook, 2001; Criss et al., 2002). Because no studies were found that have investigated gender differences in the moderating role of friendship quality, this will be investigated exploratively.

Finally, bidirectional relations will be examined in order to see whether anxiety and aggression at the first measurement 
are related to perception of interparental conflicts two years later. As this is investigated exploratively, no specific relations are hypothesized.

\section{Method}

\section{Participants}

Participants were 1292 adolescent children (623 boys, 669 girls) enrolled in the CONAMORE 2001-2006 longitudinal study (Conflict and Management of Relationships; Meeus et al., 2001). Data from the first (2001) and the third wave (2003) are used in the current study. At the first measurement 925 of the participants were early adolescents $(M=12.42, S D$ $=.59)$ and 369 were middle adolescents $(M=16.67, S D=$ .80). The average age of the total sample was 14 years $(M=$ 13.63, $S D=2.03$ ). Different education levels were represented, with approximately one-third of the adolescents being in schools preparing for blue collar work, one-third of the adolescents at schools preparing for, or at, higher education, and one-third of the adolescents at school preparing for, or at, university (because some classes are combination classes of different school levels, exact numbers cannot be provided). Regarding ethnic origin, $86 \%$ of the adolescents were Dutch, and $14 \%$ was of other origin, which resembles the general Dutch population. Most of the adolescents lived with both parents $(85.7 \%), 7.1 \%$ with their mother, $2.9 \%$ with their mother and stepfather, $0.7 \%$ with their father, $0.6 \%$ with their father and stepmother, and 3\% lived elsewhere. After removing adolescents with missing data at both Wave 1 and Wave 3, the selected samples resulted in 932 (449 boys and 483 girls) adolescents for the anxiety-related measures and 943 (456 boys and 487 girls) for aggression-related measures.

Attrition. To examine whether there were differences between the total sample and the selected sample (adolescents who filled out questionnaires in both Wave 1 and 3) in the description of the sample, and the variables used, analyses were performed. There was a difference in ethnic origin $\left(\chi^{2}(4)\right.$ $=17.64, p<.001)$ with more adolescents from other ethnic origins than Dutch represented in the group of non-selected adolescents compared to the selected adolescents. An ANOVA showed that the selected adolescents were slightly older than the non-selected $(F(1,1288)=45.82, p<.001)$. Of the nonselected, $87 \%$ were early adolescents $\left(M_{\text {years }}=13.01, S D=\right.$ 1.55) whereas $66 \%$ of the selected were early adolescents $\left(M_{\text {years }}=13.86, S D=2.14\right)$. Finally, a difference in living situation was found $\left(\chi^{2}(6)=35.83, p<.001\right)$. Non-selected adolescents were more often living with their mother, or mother and stepfather, and were less often living with both parents than the selected adolescents. No differences in gender were found.

An ANOVA showed a significant difference in aggression $(F(1,1256)=7.97, p<.01)$, where non-selected adolescents had slightly higher aggression at Wave 1 than selected adolescents. No differences were found on the other variables used in the current study.

\section{Procedure}

Adolescents from twelve high schools located in the province of Utrecht, The Netherlands, annually filled out a battery of questionnaires at school supported by research assistants. Parents and adolescents received a letter in which the aims of the study were described and if the adolescents wished to participate, they were required to provide written informed consent. For participation, adolescents received 10 euros at each wave.

\section{Measures}

Measures obtained in Wave 1 and Wave 3 of the CONAMORE study were used in the current study because adolescent perception of interparental conflict was not measured in the second wave. Thus, throughout this article, Time 1 refers to Wave 1 and Time 2 refers to Wave 3 of the CONAMORE study. All measures are adolescents' self-reports.

Perception of interparental conflict. Adolescents' perceptions of interparental conflict were assessed with an abbreviated version of two subscales, Frequency and Content, from the Children's Perception of Interparental Conflict Scale (CPIC; Grych et al., 1992). The scale contains five items (e.g., "Do your parents - as far as you know - sometimes have serious conflicts?" or "How often - as far as you know - do your parents disagree?") and adolescents indicated their answers on a five-point scale $(1=$ never to $5=$ always $)$. The scale had good internal consistency, with a Cronbach's alpha of .87 at Time 1 and .86 at Time 2. Validity is good, as scores on the subscales from which the items are used have been found to be related to parental reports of marital conflict (Grych et al., 1992; Harold et al., 1997).

Anxiety. Anxiety was assessed by means of the revised version of the Screen for Child Anxiety Related Emotional Disorders (SCARED-R; Muris \& Steerneman, 2001). In the present study, five of the eight subscales were used. Together, these scales contain 38 items measuring symptoms of separation anxiety disorder (eight items; e.g., "I am afraid that something will happen to my parents"), generalized anxiety disorder (nine items; e.g., "I worry about things working out for me"), panic disorder (13 items; e.g., "When frightened, it is difficult for me to breath"), social phobia (four items; e.g., "I am shy with people I don't know well"), and school phobia (four items; e.g., "I worry about going to school"). Respondents indicated how frequently they experience each symptom on a three-point scale $(1=$ almost never, $2=$ sometimes, $3=$ often). In a general adolescent population, the scale assesses a one-dimensional anxiety factor (Hale, Raaijmakers, Muris, \& Meeus, 2005). SCARED-R total score was obtained by summing the scores on each item for each time point separately. Reliability was high with Cronbach's alpha .94 at Time 1 and .93 at Time 2. Good validity is reported (Muris \& Steerneman, 2001).

Aggression. Aggression was assessed with the Direct and Indirect Aggression Scales (DIAS; Björkqvist, Lagerspetz, \& Österman, 1992). Two types of aggression were measured, direct (five items; e.g., "I call the other one names") and indirect aggression (twelve items; e.g., "I tell bad or false stories about the other one"). Subjects indicated on four-point scales $(1=$ never to $4=$ very often $)$ how often they displayed the behavior described when they were mad at someone in their class. A total aggression score of the two types of aggression was computed by summing the items for each wave. The scale 
has good psychometric properties (Björkqvist et al., 1992) and Cronbach's alpha in this study was .93 at Time 1 and .90 at Time 2.

Friendship quality. Positive aspects of friendships were measured by the Support subscale of the Network of Relationship Inventory (NRI) and the Balanced Relatedness, both having good psychometric properties (NRI: Furman \& Buhrmester, 1985; Balanced Relatedness: Shulman et al., 1997). The Support scale consists of 12 items (e.g., "Do you admire and respect your best friend?"). Participants indicated on a five-point scale $(1=$ a little or never to $5=$ very often $)$ the support from their best friend. The Balanced Relatedness scale measures the target adolescents' perceived tolerance of their best friend (seven items; e.g., "My best friend respects my ideas"). Participants indicated on a four-point scale ( 1 = really disagree to $4=$ really agree) to which degree the sentences fit their relationship with the best friend. Because the Tolerance and Support scales were moderately interrelated, a composite score of friendship quality was computed by summing the Tolerance and Support items for the two time points separately. To create a longitudinal measure of friendship quality, the scores of Time 1 and 2 were averaged. Pearson correlations between the Tolerance and Support were $r=.47$ at Time 1 and $r=.52$ at Time 2. Across waves they correlated $r=.30$ (Tolerance Time 1, Support Time 2) and $r=.29$ (Tolerance Time 2, Support Time 1). Reliability was high with Cronbach's alphas of the composite constructs being .93 at Time 1 and .93 at Time 2. Subsequently, three friendship quality groups were constructed by percentiles to ensure an equal sample distribution in the groups. Below the $25^{\text {th }}$ percentile were adolescents with low-quality (Anxiety: $N=239,115$ boys and 124 girls; Aggression: $N=241,118$ boys and 123 girls), above and below the $50^{\text {th }}$ percentile were normal-quality (Anxiety: $N=441,207$ boys and 234 girls; Aggression: $N=$ 455,214 boys and 241 girls), and above the higher $25^{\text {th }}$ percentile were high-quality (Anxiety: $N=252,127$ boys and 125 girls; Aggression: $N=247,124$ boys and 123 girls). Friendship quality groups were made for boys and girls separately, in order to account for the interrelatedness of gender and friendship quality because boys reported significantly lower friendship quality than girls.

\section{Statistical procedure}

Missing data were imputed on item level by means of the Relative Mean Substitution method (RMS; Raaijmakers, 1999). Subsequently, data files for anxiety and aggression, respectively, were constructed with deletion of the cases not participating at both Time 1 and Time 2. Due to skewed outcome variables, all analyses were also conducted with Logarithmic transformations. Because this did not change results, the original variables were retained.

The relation between adolescent perception of interparental conflict and anxiety and aggression, respectively, was examined separately. Structural equation modeling was used to analyze the relation between adolescents' perceptions of interparental conflict and maladjustment (i.e., the initial baseline model). A series of AMOS multigroup analyses were performed, in order to examine the moderating effect of friendship quality and possible gender differences in the moderating effect. Maximum Likelihood Estimation was used and model fits were evaluated by the following indices: Chi-square, RMR, CFI, and GFI (Kline, 2005). Significant differences between groups were investigated with critical ratios with values above $+/-1.96$ being significant.

\section{Results}

\section{Descriptive results}

Table 1 provides means, standard deviations, and correlations within and across waves for anxiety and aggression. Adolescents' perceptions of interparental conflict were positively correlated with both anxiety and aggression within and across the two time points. Moreover, friendship quality was negatively related to both anxiety and aggression at both waves. ANOVAs showed an interaction between gender and friendship quality $(F(2,926)=3.64, p<.05)$ for conflict perception at Time 1 . Boys with low friendship quality had the highest perception of conflict, whereas girls with normal friendship quality had highest conflict perception. Moreover, there was an interaction between gender and friendship quality regarding anxiety $(F(2,926)=6.85, p<.01$ anxiety at Time $1 ; F(2,926)$ $=3.95, p<.05$ anxiety at Time 2 ). The mean difference of anxiety between low and normal friendship quality was larger for boys than for girls with low friendship quality having higher

Table 1

Means, standard deviations, and bivariate correlations within and across waves for all variables

\begin{tabular}{|c|c|c|c|c|c|c|c|}
\hline Variable & 1 & 2 & 3 & 4 & 5 & 6 & 7 \\
\hline 1. Conflict perception $\mathrm{T} 1$ & - & 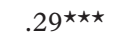 & $.18^{\star \star \star}$ & $.44^{\star \star \star}$ & $.18^{\star \star \star}$ & $.06^{\star}$ & -.03 \\
\hline 2. Anxiety $\mathrm{T} 1$ & $.29 \star \star \star$ & - & $.19^{\star \star \star}$ & $.13^{\star \star \star}$ & $.44^{\star \star \star}$ & $.12^{\star \star}$ & $-.13^{\star \star \star}$ \\
\hline 3. Aggression $\mathrm{T} 1$ & $.18^{\star \star \star}$ & $.19^{\star \star \star}$ & - & .04 & $.08^{\star}$ & $.42^{\star \star}$ & $-.14^{\star \star \star}$ \\
\hline 4. Conflict perception $\mathrm{T} 2$ & $.44^{\star \star \star}$ & $.13^{\star \star \star}$ & .04 & - & $.28^{\star \star \star}$ & $.13^{\star \star}$ & -.04 \\
\hline 5. Anxiety $\mathrm{T} 2$ & $.19^{\star \star}$ & $.44^{\star \star \star}$ & $.08^{\star}$ & $.28^{\star \star \star}$ & - & $.22^{\star \star \star}$ & $-.13^{\star \star \star}$ \\
\hline 6. Aggression T2 & $.06^{\star}$ & $.10^{\star \star}$ & $.43^{\star \star \star}$ & $.13^{\star \star \star}$ & $.20^{\star \star \star}$ & - & $-.21^{\star \star \star}$ \\
\hline 7. Friendship quality & -.01 & $-.13^{\star \star \star}$ & $-.14^{\star \star \star}$ & -.02 & $-.11^{\star \star}$ & $-.20 \star \star \star$ & - \\
\hline$M$ & 1.77 & 1.31 & 1.42 & 1.87 & 1.28 & 1.41 & 6.33 \\
\hline$S D$ & .76 & .30 & .44 & .74 & .26 & .40 & .98 \\
\hline
\end{tabular}

Note. Anxiety: below the diagonal, $N=932$; Aggression: above the diagonal, $N=943$.

$\star \star \star p<.001 ;{ }^{\star \star} p<.01 ;{ }^{\star} p<.05$. 
scores on anxiety. For aggression at Time 1 a main effect of gender was significant $(F(1,939)=60.91, p<.001)$ with boys having a slightly higher level of aggression than girls. For aggression at Time 2 there was an interaction between gender and friendship quality $(F(2,937)=7.26, p<.001)$. Friendship quality was less important for girls' levels of aggression than for boys'.

\section{Adolescent perception of interparental conflict and adjustment}

The first research question concerned the relation between adolescents' perceptions of interparental conflict and anxiety and aggression, respectively. To examine this, the initial baseline models including both genders were estimated. Figure 1 shows the conceptual model with which the hypotheses were tested examining the cross-sectional paths (path B), the correlated change (path $\mathrm{C}$ ), and the cross-lagged paths (path A). Significant correlations at Time 1 (path B) would indicate initial relations between interparental conflict and the outcome variable. Significant correlations of residuals change scores at Time 2 (path C) indicate whether correlated change is present (Neyer \& Asendorpf, 2001). Significant relations between perception of interparental conflict at Time 1 and anxiety or aggression at Time 2 (path A) would indicate effects over time of interparental conflict on the outcome variable.

Table 2 provides the model fit for this baseline model. For both anxiety and aggression, the fit indices signified a good fit of the model. Table 3 provides the standardized path coefficients and correlations. In agreement with our hypothesis, both the initial correlation of conflict perception and anxiety and the correlated change were significant. The over-time association was also significant. Regarding aggression the initial correlation and the correlated change were significant. No relation over time was found. The significant correlated change means that after controlling for the initial correlation, the stability paths, and the cross-lagged paths, change in conflict perception was positively related to change in anxiety and aggression. Thus, our hypothesis was fully met for anxiety and partially for aggression, as no effect over time was found.

\section{Friendship quality as a moderator}

Secondly, we examined whether friendship quality functioned as a moderator of the association between adolescent percep-

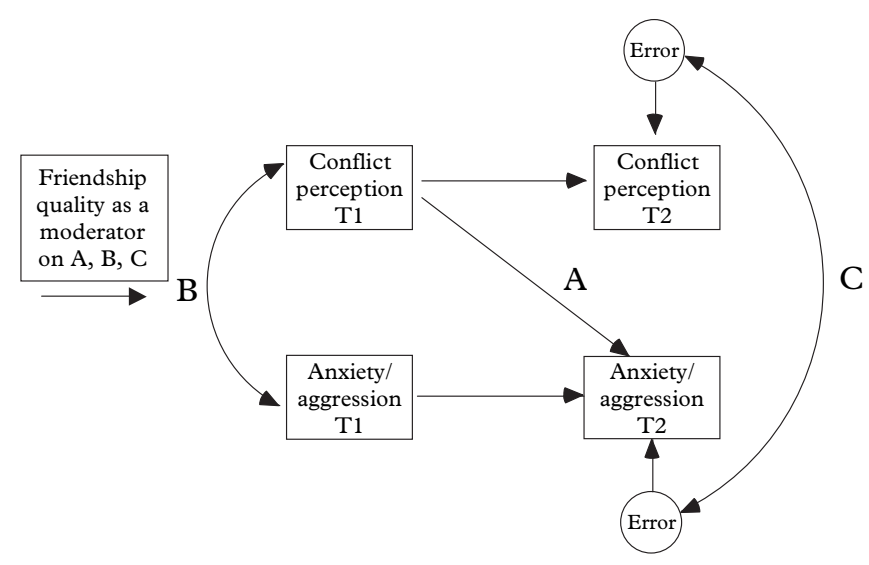

Figure 1. Conceptual model.
Table 2

Model comparisons and fit indices of the initial model

\begin{tabular}{lccccc}
\hline Model & $\chi^{2}$ & $d f$ & RMR & GFI & CFI \\
\hline $\begin{array}{l}\text { Anxiety } \\
\quad \text { Initial model }\end{array}$ & .06 & 1 & .00 & 1.00 & 1.00 \\
$\begin{array}{l}\text { Aggression } \\
\text { Initial Model }\end{array}$ & 1.66 & 1 & .00 & 1.00 & 1.00 \\
\hline
\end{tabular}

Note. Anxiety: $N=932$; Aggression: $N=943 . R M R=$ standardized root mean square residual; $G F I=$ goodness of fit index; $C F I=$ comparative fit index.

${ }^{\star \star \star} p<.001 ;{ }^{\star \star} p<.01 ;{ }^{\star} p<.05$.

Table 3

Standardized path coefficients and correlations of the initial model

\begin{tabular}{lll}
\hline Correlations and regression paths & Anxiety & Aggression \\
\hline & \multicolumn{2}{c}{$r$} \\
Conflict perception T1 $\leftrightarrow$ adjustment T1 & $.29^{\star \star \star}$ & $.18^{\star \star \star}$ \\
Conflict perception T2 $\leftrightarrow$ adjustment T2 & $.24^{\star \star \star}$ & $.15^{\star \star \star}$ \\
& \multicolumn{2}{c}{$\beta$} \\
Conflict perception T1 $\rightarrow$ adjustment T2 & $.07^{\star}$ & -.01 \\
Conflict perception T1 $\rightarrow$ conflict perception T2 & $.44^{\star \star \star}$ & $.44^{\star \star \star}$ \\
Adjustment T1 $\rightarrow$ adjustment T2 & $.42^{\star \star \star}$ & $.43^{\star \star \star}$ \\
\hline
\end{tabular}

Note. ${ }^{\star \star \star} p<.001 ;{ }^{\star \star} p<.01 ;{ }^{\star} p<.05$.

tion of interparental conflict and anxiety and aggression, respectively. For a buffering effect to be present, the associations between adolescent interparental conflict perception and problem behavior should be less strong for adolescents with high friendship quality than for adolescents with normal friendship quality. Conversely, for friendship quality to be a risk factor, the associations between adolescents' conflict perception and problem behavior should be stronger for adolescents with low quality friendship than for adolescents with normal friendship quality. As a stringent test of our hypotheses, all group differences should be significant.

The first model, estimated for both anxiety and aggression, was fully constrained with all paths, initial correlations, variances, and covariances constrained across friendship quality groups and gender. Model $2 \mathrm{a}$ constrained the paths examined (see Figure 1), and left the other paths unconstrained. Two additional versions of Model 2a were constructed to recognize whether group differences were due to gender or friendship quality differences. Model $2 \mathrm{~b}$ constrained paths $\mathrm{A}, \mathrm{B}$, and C, for gender, and Model 2c constrained paths A, B, and C for friendship quality. In Model 3, the paths A, B, and C were left unconstrained, to investigate whether setting them free would increase the fit significantly. Table 4 provides the model fit indices of the compared nested models.

Anxiety. For Anxiety, Model 2b designated the best-fitting model with a relatively low, insignificant chi square and other fit indices showing a very good fit. Additionally, there was a significant chi square decrease from Model 2a to Model 2b (see Table 4). Consequently, for anxiety, the moderating effect of friendship quality was examined for boys and girls together because no gender differences were found. The fit indices of the nested 
Table 4

Model comparisons and fit indices for nested models with friendship quality and gender as moderators

\begin{tabular}{|c|c|c|c|c|c|c|c|}
\hline Model & $\chi^{2}$ & $d f$ & RMR & GFI & CFI & $\Delta \chi^{2}$ & $\Delta d f$ \\
\hline \multicolumn{8}{|l|}{ Anxiety } \\
\hline Model 1 & $226.44^{\star \star \star}$ & 51 & .06 & .86 & .68 & & \\
\hline Model 2a & $33.61^{\star}$ & 21 & .02 & .98 & .98 & & \\
\hline Model 2b & 18.84 & 15 & .02 & .99 & .99 & & \\
\hline Model 2c & $30.39^{\star}$ & 18 & .02 & .98 & .98 & & \\
\hline Model 3 & 6.06 & 6 & .01 & 1.00 & 1.00 & & \\
\hline Difference 1 and 2 & & & & & & $232.83^{\star \star}$ & 30 \\
\hline Difference $2 a$ and $2 b$ & & & & & & $14.77^{\star}$ & 6 \\
\hline Difference $2 \mathrm{a}$ and $2 \mathrm{c}$ & & & & & & 3.22 & 3 \\
\hline Difference $2 b$ and 3 & & & & & & 12.78 & 9 \\
\hline \multicolumn{8}{|l|}{ Aggression } \\
\hline Model 1 & $269.85^{\star \star \star}$ & 51 & .07 & .87 & .51 & & \\
\hline Model 2a & $44.37^{\star \star}$ & 21 & .03 & .98 & .95 & & \\
\hline Model 2b & $35.97^{\star \star}$ & 15 & .03 & .98 & .95 & & \\
\hline Model 2c & $38.50^{\star \star}$ & 18 & .03 & .98 & .95 & & \\
\hline Model 3 & 4.66 & 6 & .01 & 1.00 & 1.00 & & \\
\hline Difference 1 and 2a & & & & & & $225.48^{\star \star}$ & 30 \\
\hline Difference $2 a$ and $2 b$ & & & & & & 8.4 & 6 \\
\hline Difference $2 \mathrm{a}$ and $2 \mathrm{c}$ & & & & & & 5.87 & 3 \\
\hline Difference $2 \mathrm{a}$ and 3 & & & & & & $39.71^{\star \star}$ & 15 \\
\hline
\end{tabular}

Note. Anxiety: low $N=115$ boys, 124 girls; normal $N=207$ boys, 234 girls; high $N=$ 127 boys, 125 girls. Aggression: low $N=118$ boys, 123 girls; normal $N=214$ boys, 241 girls; high $N=124$ boys, 123 girls. $R M R=$ standardized root mean square residual; $G F I=$ goodness of fit index; $C F I=$ comparative fit index. Model 1: fully constrained; Model 2a: paths A, B, and C constrained for both friendship quality and gender; Model 2b: paths A, B, and C constrained for gender; Model 2c: paths A, B, C constrained for friendship quality; Model 3: fully unconstrained.

${ }^{\star \star \star} p<.001 ;{ }^{\star \star} p<.01 ;{ }^{\star} p<.05$.

models for boys and girls together are provided in Table 5 . Similar model building as above was utilized. In this case, the fully unconstrained Model 3, with friendship quality groups allowed to differ, designated the best-fitting model for anxiety.

Table 6 provides the initial correlations, the correlated change, and the standardized path coefficients. For adolescents with high friendship quality, the initial correlation between perceived conflict and anxiety, the correlated change, and the over-time association were not significantly different from the estimations for adolescents with normal friendship quality. Thus, the hypothesis regarding a buffering effect of high friendship quality against the effects of perceived interparental conflict for anxiety was not supported.
For low friendship quality, the significant initial correlation between perceived interparental conflict and anxiety was positive and of moderate size. The correlated change was also significant, denoting that change in perceived interparental conflict was positively related to change in anxiety. Additionally, the effect of perceived interparental conflicts at Time 1 on anxiety two years later was marginally significant. This indicates that there may be an effect over time of interparental conflict perceptions on anxiety for low friendship quality adolescents. Examination of critical ratios showed that there was a significant difference between low friendship quality and the reference group, normal friendship quality, for the initial correlation $(C R=-2.77)$. Furthermore, there was a significant

Table 5

Model comparisons and fit indices for anxiety boys and girls together

\begin{tabular}{lcrrrrrr}
\hline Model & $\chi^{2}$ & $d f$ & RMR & GFI & CFI & $\Delta \chi^{2}$ & $\Delta d f$ \\
\hline Anxiety & & & & & & & \\
$\quad$ Model 1 & $133.26^{\star \star \star}$ & 21 & .04 & .93 & .80 & & \\
Model 2 & $22.32^{\star \star}$ & 9 & .02 & .99 & .98 & & \\
Model 3 & 5.27 & 3 & .01 & 1.00 & 1.00 & & \\
Difference 1 and 2 & & & & & & $110.94^{\star \star}$ & 12 \\
Difference 2 and 3 & & & & & & $17.05^{\star \star}$ & 6
\end{tabular}

Note. $N=932 . R M R=$ standardized root mean square residual; $G F I=$ goodness of fit index; $C F I=$ comparative fit index. Model 1: fully constrained; Model 2: paths A, B, and C constrained; Model 3: fully unconstrained.

${ }^{\star \star \star} p<.001 ;{ }^{\star \star} p<.01 ;{ }^{\star} p<.05$. 
Table 6

Standardized path coefficients and correlations of final models for anxiety and aggression

\begin{tabular}{|c|c|c|c|c|c|c|}
\hline Correlations and regression paths & Low & Normal & High & Low & Normal & High \\
\hline Anxiety & & $r$ & & & & \\
\hline Conflict perception $\mathrm{T} 1 \leftrightarrow$ anxiety $\mathrm{T} 1$ & $.37 \star \star \star a$ & $.25^{\star \star \star b}$ & $.23^{\star \star \star b}$ & & & \\
\hline \multirow{2}{*}{ Conflict perception $\mathrm{T} 2 \leftrightarrow$ anxiety $\mathrm{T} 2$} & $.31^{\star \star \star \mathrm{a}}$ & $.22^{\star \star \star b}$ & $.22^{\star \star \star b}$ & & & \\
\hline & & $\beta$ & & & & \\
\hline Conflict perception $\mathrm{T} 1 \rightarrow$ anxiety $\mathrm{T} 2$ & $.12^{+b}$ & $.03^{\mathrm{b}}$ & $.10^{\mathrm{b}}$ & & & \\
\hline Conflict perception $\mathrm{T} 1 \rightarrow$ conflict per. $\mathrm{T} 2$ & $.32^{\star \star \star}$ & $.48^{\star \star \star}$ & $.49^{\star \star \star}$ & & & \\
\hline Anxiety $\mathrm{T} 1 \rightarrow$ anxiety $\mathrm{T} 2$ & $.24^{\star \star \star}$ & $.50^{\star \star \star}$ & $.48^{\star \star \star}$ & & & \\
\hline \multirow[t]{2}{*}{ Aggression } & & Boys & & \multicolumn{3}{|c|}{ Girls } \\
\hline & & & & & & \\
\hline Conflict perception $\mathrm{T} 1 \leftrightarrow$ aggression $\mathrm{T} 1$ & $.25^{\star \star b}$ & $.10^{\mathrm{b}}$ & $.40^{\star \star \star a}$ & $.16^{\mathrm{b}}$ & $.23^{\star \star \star b}$ & $.08^{\mathrm{b}}$ \\
\hline \multirow[t]{2}{*}{ Conflict perception $\mathrm{T} 2 \leftrightarrow$ aggression $\mathrm{T} 2$} & $.39^{\star \star \star a}$ & $.09^{\mathrm{b}}$ & $.04^{\mathrm{b}}$ & $.16^{\mathrm{b}}$ & $.14^{\star \mathrm{b}}$ & $.23 \star b$ \\
\hline & \multicolumn{6}{|c|}{$\beta$} \\
\hline Conflict perception $\mathrm{T} 1 \rightarrow$ aggression $\mathrm{T} 2$ & $.18^{\star \mathrm{a}}$ & $-.09^{\mathrm{b}}$ & $-.07^{\mathrm{a}}$ & $-.01^{\mathrm{b}}$ & $-.05^{\mathrm{b}}$ & $-.10^{\mathrm{b}}$ \\
\hline Conflict perception $\mathrm{T} 1 \rightarrow$ conflict per. $\mathrm{T} 2$ & $.19^{\star}$ & $.44^{\star \star \star}$ & $.37^{\star \star \star}$ & $.45^{\star \star \star}$ & $.50^{\star \star \star}$ & $.61^{\star \star \star}$ \\
\hline Aggression $\mathrm{T} 1 \rightarrow$ aggression $\mathrm{T} 2$ & $.27^{\star \star \star}$ & $.36^{\star \star \star}$ & $.39^{\star \star \star}$ & $.35^{\star \star \star}$ & $.45^{\star \star \star}$ & $.45^{\star \star \star}$ \\
\hline
\end{tabular}

Note. ${ }^{\star \star \star} p<.001 ;{ }^{\star \star} p<.01 ;{ }^{\star} p<.05 .{ }^{+}$marginal significant $(p=.06)$. Different superscripts indicate significant differences between low and normal and/or high and normal within gender.

difference between low and normal friendship quality $(C R=$ $-2.27)$ for the correlated change. The difference between low and normal friendship quality for the time effect was not significant $(C R=-1.30)$. Thus, support was found for the hypothesis regarding low friendship quality as a risk factor for anxiety problems when adolescents perceive interparental conflicts.

Aggression. For aggression, Model 3a fully unconstrained model with both gender and friendship quality allowed to differ had the best model fit (see Table 4). This was supported by a very low and insignificant chi square, perfect fit indices, and a significant chi square decrease from Model 2a to Model 3. Accordingly, a model allowing interactions between gender and friendship quality was subsequently discussed.

For boys with high friendship quality, the initial correlation was positive, significant, and of moderate size, which was an unexpected result because we anticipated it to be low, unrelated, and/or negative (see Table 6). The correlated change and the time effect were not significant. There was a significant group difference between high and normal friendship quality for the initial correlation $(C R=2.94)$ and for the time effect $(C R=2.09)$. The initial correlation was higher for the high friendship quality than for normal friendship quality. The time effect for high quality was lower than for normal, although both were negative relations. Thus, for boys, partial support was found for the hypothesis regarding a buffering effect of high friendship quality against aggressive behavior.

For boys with low friendship quality, both the initial correlation and the correlated change of perceived conflicts and aggression were significant. Perceived interparental conflicts were also significantly related to aggressive behavior two years later. This means that aggressive behavior increased over time for adolescents with high interparental conflict perceptions, if they had low friendship quality. Critical ratios showed that the difference between low and normal friend- ship quality for the initial correlation was not significant $(C R$ $=-1.30)$. There was a significant difference between low and normal friendship quality for the correlated change $(C R=$ -3.01). Furthermore, the difference between low and normal friendship quality for the time effect was significant $(C R=$ $-2.41)$. Consequently, for boys, support was found for the hypothesis regarding low friendship quality as a risk factor for aggressive behavior.

For girls with high friendship quality, the initial correlation and the over-time association between perception of interparental conflicts and later aggression were not significant (see Table 6). Nevertheless, the correlated change was significant, which was a rather unexpected finding. Group differences were not significant when comparing with normal friendship quality. Therefore, no evidence was found for the hypothesis regarding a buffering effect of high friendship quality against aggressive behavior for girls.

Neither the correlations nor the time effect were significant for girls with low friendship quality. When comparing with normal friendship quality, the group differences were not significant. Thus, we did not find any support for girls' low friendship quality as being a risk factor for aggression.

To scrutinize differences across gender in the examined relations with aggression, boys with high friendship quality were compared to girls with high friendship quality. This was also done for normal and low friendship quality. For high quality there was a significant difference between boys and girls in the initial correlation $(C R=-2.99)$ and the time effect $(C R=-1.98)$. Boys had a stronger positive association between perceptions of interparental conflicts at Time 1 than girls. Girls had a slightly stronger negative time effect than boys, but neither effect was significant. For low friendship quality there was a significant difference between boys and girls in the correlated change $(C R=-2.79)$ and the time effect $(C R=$ $-2.31)$. Boys had a higher correlated change than girls, and girls' correlated change was not significant. Whereas boys' time 
effect of perceived interparental conflicts on later aggression was positive and significant, there was no time effect for girls. There were no significant differences between boys and girls with normal friendship quality.

Bidirectional relations. Finally, bidirectional relationships were examined in an exploratory manner, in order to see whether anxiety and aggression at Time 1 , respectively, were related to later perceptions of interparental conflicts at Time 2. These relations were present neither for anxiety nor for aggression.

\section{Discussion}

The overall endeavor of this study was to examine the association between adolescents' perceptions of interparental conflicts and internalizing and externalizing problems, by investigating the moderating role of adolescent friendship quality. We found support for the notion that low friendship quality was a risk factor for these adjustment problems, and only limited support for a buffering effect of high friendship quality.

The most important contribution of this study is that, both longitudinally and within time frames, low friendship quality was found to be a risk factor for adolescent anxiety and aggression in relation to their perception of interparental conflicts: When adolescents had low friendship quality, the associations between perception of interparental conflicts and psychosocial adjustment were stronger compared to normal friendship quality. Regarding anxiety, this finding applies to both boys and girls, whereas this is only found for boys when aggression is considered.

The findings of our study extend those of Wasserstein and La Creca (1996) and show that friendship quality can be characterized as a moderator of the association between perception of interparental conflicts and maladjustment, also in adolescence. Further, the results clearly reveal the importance of distinguishing a buffer and a risk effect. An explanation of why low friendship quality is a risk factor in relation to interparental conflicts may be that, when adolescents have a low friendship quality, they are deficient in social support. Therefore, they are not able to confide in a close friend and receive the necessary support that may protect against the adverse effects of perception of interparental conflicts (Gauze et al., 1996; Lansford et al., 2003).

Our results did not provide convincing support for the hypothesis regarding a buffering effect of high friendship quality against anxiety and aggression in relation to perceptions of interparental conflict. Although there was an indication of a buffering effect for anxiety, the differences between the group of high friendship quality and the group of normal quality were not significant. For boys and aggression, the standardized coefficients of time effects for normal and high friendship quality, respectively, were of very small difference.

These results suggest that the negative effects of adolescents perceiving high interparental conflicts are not likely to be buffered by support from other sources. Conversely, they are exacerbated by the lack of support from other sources. In line with previous research, these findings clearly denote that high perception of interparental conflicts is generally a risk factor for children and adolescents (Cummings \& Davies, 2002; Cummings et al., 2003; Davies et al., 1999; Davies, SturgeApple, Winter, Cummings, E.M., \& Farrell, D., 2006; van der
Valk, 2004). However, the crucial message is that there is an extra, additive risk effect for adolescents who have low-quality friendships. Perhaps the lack of compensation from high friendship quality is due to the adolescents' rather young age in this sample. It may be that the increase in the psychological importance and intimacy of close friends, usually developing from early adolescence (Sullivan, 1953), has not yet begun for some of the adolescents. Thus, the lack of buffering effects may be due to the friendship's maturity.

These findings support the hypothesis of Baumeister and colleagues (2001) that "bad is stronger than good". They argue for the greater power of bad events and relationships, weighed against good and positive ones, as a general principle across a range of psychological phenomena. According to the authors, negative support from friends weighs more heavily than positive support. By comparing groups of adolescents with negative and positive friendship quality with a neutral reference group (i.e., normal friendship quality), we were better able to distinguish the effects of "bad" and "good". In line with Baumeister and colleagues (2001), our findings show that helpful and supportive aspects seem to have weaker relations to adjustment than unhelpful and less supportive aspects. The general pattern for both anxiety and aggression is that it does not matter whether adolescents have high or normal friendship quality. Perhaps normal friendship quality suffices in providing opportunities for adolescents to confide in a friend and receive support, which can promote feelings of well-being and decrease maladjustment.

Another interesting finding of this study pertains to the gender difference in the moderating role of friendship quality. Friendship quality had the same moderating effect for boys and girls regarding anxiety. This might indicate that, although adolescent boys and girls can differ in their conceptualizations of friendships, the lack of reimbursement of high friendship quality and the additional risk effect of low quality is the same for both genders (Gauze et al., 1996). For aggressive behavior, friendship quality did not moderate the relation between perceived interparental conflicts for girls, though it did for boys. Boys with low friendship quality reported more aggressive behavior in reaction to interparental conflict than boys with normal friendship quality, and these group differences were significant. Therefore, low friendship quality is worse for boys than for girls, and thus more important for boys' level of aggression than for that of girls. Even though the nature of girls' friendships may be more intimate and supporting (Crawford et al., 2001; Criss et al., 2002), friendships are not necessarily a more important buffer for girls than for boys. A reason for this could be that aggression is less strongly related to friendship quality for girls than for boys. Boys may be more vulnerable to antisocial peers exhibiting aggressive behavior because they withdraw more from unsatisfactory family environments than do girls (Hetherington, 1999). This result can be related to Hetherington's (1999) findings regarding strong associations between antisocial peers and adolescent externalizing behavior (via mother authoritative parenting) for children whose parents had many marital conflicts. It may be that adolescents exposed to high interparental conflict spend more unsupervised time with antisocial peers. Adolescents' associations with deviant peers appear to be a risk factor of externalizing problems (Deković, 1999). Because we only found mean differences in conflict perception for the respective friendship quality groups in interaction with gender, this could be accurate for boys. Thus, for boys, perception of inter- 
parental conflicts may be negatively related with friendship quality. The combination of high interparental conflict perceptions and low friendship quality, for boys, could be an indicator of an accumulation of stresses or multiple risks, where the amount of risk may give a stronger variation in adjustment than the amount of protective factors (Deković, 1999). The adolescent boy is already at risk because he reports high interparental conflict perception and he is additionally at risk because he has low friendship quality. Future studies should examine gender differences more thoroughly.

A strength of the current study is the longitudinal design. Literature on potential moderators of the linkages between perceived interparental conflicts and child adjustment is very scarce. To our knowledge, this is the first longitudinal study examining this link while including the role of friendship quality. Because experiments are not a feasible means of investigation for this topic, longitudinal correlational studies are crucial in revealing time effects. Moreover, they provide the best opportunity to study developmental mechanisms and moderators that link interparental discord and child adjustment (Fincham, Grych, \& Osborne, 1994). These longitudinal findings strengthen our conclusions regarding a moderating effect of friendship quality on the relations between adolescent perception of interparental conflicts and adjustment. Although effect sizes over time were generally small, these are in line with findings of other studies controlling for initial correlations and stability effects (Neyer \& Asendorpf, 2001). The relatively small subsamples of the different groups in the multigroup models may have produced a non-significance of effects that were significant for the total group.

Additionally, the use of a reference group (i.e., normal friendship quality), to which high and low friendship quality, respectively, are compared, makes it feasible to differentiate between buffer and risk effects. This enabled the study to reveal that friendship quality is operating as a risk factor, instead of as a buffer or protective factor, in the relation between perception of interparental conflicts and adolescent adjustment.

In the current study, adolescents' self-reports were utilized. By including adolescents' perceptions, we were certain that the adolescent noticed the conflicts. Conflict perception can be viewed as a crucial proxy to actual conflict, because regarding their adjustment, it is essential whether and how adolescents perceive the conflicts (Grych \& Fincham, 1993; Grych et al., 1992; Laursen, 1993).

Despite these strengths, this study has a number of limitations. In the study, we used the same source of information for all constructs, as all measures are adolescent self-reports. Consequently, the data were not independent and the results may be inflated by a potential reporter bias. Future research should utilize multiple informants to avoid this problem. However, the use of a single-reporter data cannot explain the most important finding of the current study, that is, the moderating role of friendship quality, as reporter bias would be expected to affect results similarly for all groups. Nevertheless, it would increase construct validity to use multiple reporters or observational methods.

Future research should take into account information on the peer network as a whole, because this study looked at friendship quality with one best friend. The focus is, hence, on more qualitative aspects of the relationship with a best friend, whereas quantitative aspects may also be important. Furthermore, future research should also distinguish between pro- social and antisocial support from friends, as it would be useful to know whether low-quality friendship is of a more antisocial character than high-quality.

To conclude, the results of this study demonstrate, once again, that the family remains important for children - also when they reach early and middle adolescence. That is, interparental conflicts are related to both internalizing and externalizing problems of adolescents. Well-functioning marital relationships may provide a secure base as a bridge between the child and the world around them (Cummings, Schermerhorn, Davies, Goeke-Morey, \& Cummings, 2006; Markiewicz, Doyle, \& Brendgen, 2001). Moreover, the findings indisputably underline that relationship systems function together in their influence on psychosocial well-being during adolescence (Furman \& Buhrmester, 1985; Gauze et al., 1996). We found evidence for low friendship quality as a risk factor for both boys and girls regarding anxiety, and for boys regarding aggression, but we did not find that high friendship quality protects against the effects on adjustment of perception of interparental conflicts. The substantial impact of not having a low quality friendship when perceiving interparental conflicts is clear. Furthermore, a normal friendship quality is good enough to be a possible source of resiliency that mitigates the adverse effects of perceiving interparental conflicts.

\section{References}

Amato, P.R., \& Keith, B. (1991). Parental divorce and adult well-being: A metaanalyses. Fournal of Marriage and the Family, 53, 43-58.

Bagwell, C.L., Bender, S.E., Andreassi, C.L., Kinoshita, T.L., Montarello, S.A., \& Muller, J.G. (2005). Friendship quality and perceived relationship changes predict psychosocial adjustment in early adulthood. Fournal of Social and Personal Relationships, 22, 235-254.

Baumeister, R.F., Bratslavsky, E., Finkenauer, C., \& Vohs, K.D. (2001). Bad is stronger than good. Review of General Psychology, 5, 323-370.

Björkqvist, K., Lagerspetz, K.M.J., \& Österman, K. (1992). The Direct and Indirect Aggression Scales. Vasa, Finland: Abo Akademi University, Department of Social Sciences.

Bronfenbrenner, U., \& Morris, P.A. (1998). The ecology of developmental processes. In W. Damon (Ed.). The Handbook of Child Psychology (5th ed., Vol. 1, pp. 993-1028). New York: Riley.

Buehler, C., Anthony, C., Krishnakumar, A., Stone, G., Gerard, J., \& Pemberton, S. (1997). Interparental conflict and youth problem behaviors: A metaanalysis. Fournal of Child and Family Studies, 6, 233-247.

Buehler, C., Krishnakumar, A., Stone, G., Anthony, C., Pemberton, S., \& Gerard, J. (1998). Interparental conflict styles and youth problem behaviors: A two-sample replication study. Fournal of Marriage and the Family, 60, 119-133.

Buist, K.L., Deković, M., Meeus, W., \& van Aken, M.A.G. (2002). Developmental patterns in adolescent attachment to mother, father, and sibling. fournal of Youth and Adolescence, 31, 167-176.

Crawford, T.N., Cohen, P., Midlarsky, E., \& Brook J.S. (2001). Internalizing symptoms in adolescents: Gender differences in vulnerability to parental distress and discord. Fournal of Research on Adolescence, 11, 95-118.

Criss, M.M., Pettit, G.S., Bates, J.E., Dodge, K.A., \& Lapp, A.L. (2002). Family adversity, positive peer relationships, and children's externalizing behavior: A longitudinal perspective on risk and resilience. Child Development, 73, 1220-1237.

Cummings, E.M., \& Davies, P.T. (2002). Effects of marital conflict on children: Recent advances and emerging themes in process-oriented research. Fournal of Child Psychology and Psychiatry, 43, 31-63.

Cummings, E.M., Davies, P.T., \& Simpson, K.S. (1994). Marital conflict, gender, and children's appraisals and coping efficacy as mediators of child adjustment. Fournal of Family Psychology, 8, 141-149.

Cummings, E.M., Goeke-Morey, M.C., \& Papp, L.M. (2003). Children's responses to everyday marital conflict tactics in the home. Child Development, 74, 1918-1929.

Cummings, E.M., Schermerhorn, A.C., Davies, P.T., Goeke-Morey, M.C., \& Cummings, J.S. (2006). Interparental discord and child adjustment: 
Prospective investigations of emotional security as an explanatory mechanism. Child Development, 77, 132-152.

Davies, P.T., Dumenci, L., \& Windle, M. (1999).The interplay between maternal depressive symptoms and marital distress in the prediction of adolescent adjustment. Fournal of Marriage and the Family, 61, 238-254.

Davies, P.T., Sturge-Apple, M.L., Winter, M.A., Cummings, E.M., \& Farrell, D. (2006). Child adaptational development in context of interparental conflict over time. Child Development, 77, 218-233.

Davies, P.T., \& Windle, M. (2001). Interparental discord and adolescent adjustment trajectories: The potentiating and protective role of intrapersonal attributes. Child Development, 72, 1163-1178.

Deković, M. (1999). Risk and protective factors in the development of problem behavior during adolescence. Fournal of Youth and Adolescence, 26, 667-685.

Fincham, F.D., Grych, J.H., \& Osborne, L.N. (1994). Does marital conflict cause child maladjustment? Directions and challenges for longitudinal research. Fournal Family Psychology, 8, 128-140.

Furman, W., \& Buhrmester, D. (1985). Children's perceptions of the personal relationship in their social networks. Developmental Psychology, 21, 1016-1024.

Gable, S., Belsky, J., \& Crnic, K. (1992). Marriage, parenting, and child development: Progress and prospects. Fournal of Family Psychology, 5, 276-294.

Gauze, C., Bukowski, W.M., Aquan-Assee, J., \& Sippola, L.K. (1996). Interactions between family environment and friendship and associations with self-perceived well-being during early adolescence. Child Development, 67, 2201-2216.

Gerard, J.M., Buehler, C., Franck, K., \& Anderson, O. (2005). In the eyes of the beholder: Cognitive appraisals as mediators of the association between interparental conflict and youth maladjustment. Fournal of Family Psychology, 19, 376-384.

Grych, J.H., \& Fincham, F.D. (1990). Marital conflict and children's adjustment: A cognitive-contextual framework. Psychological Bulletin, 108, 267-290.

Grych, J.H., \& Fincham, F.D. (1993). Children's appraisals of marital conflict: Initial investigations of the cognitive-contextual framework. Child Development, 64, 215-230.

Grych, J.H., Seid, M., \& Fincham, F.D. (1992). Assessing marital conflict from the child's perspective: The children's perception of interparental conflict scale. Child Development, 63, 558-572.

Hale, W.W. III, Raaijmakers, Q., Muris, P., \& Meeus, W. (2005). Psychometric properties of the Screen for Child Anxiety Related Emotional Disorders (SCARED) in the general adolescent population. Fournal of American Academic Child and Adolescent Psychiatry, 44, 283-290.

Harold, G.T., Fincham, F.D., Osborne, L.N., \& Conger, R.D. (1997). Mom and dad are at it again: Adolescent perceptions of marital conflict and adolescent psychological distress. Developmental Psychology, 33, 333-350.

Hartup, W.W. (1996). The company they keep: Friendships and their developmental significance. Child Development, 67, 1-13.

Hartup, W.W. \& Stevens, N. (1997). Friendships and adaptation in the life course. Psychological Bulletin, 121, 355-370.

Hetherington, E.M. (1999). Should we stay together for the sake of the children? In E.M. Hetherington (Ed.), Coping with divorce, single parenting, and remarriage. A risk and resiliency perspective (pp. 93-116). Mahwah, New Jersey: Lawrence Erlbaum Associates.

Hetherington, E.M., \& Stanley-Hagan, M.M. (1999). The adjustment of children with divorced parents: A risk and resiliency perspective. fournal of Child Psychology and Psychiatry, 40, 129-140.

Johnson, H.D., LaVoie, J.C., \& Mahoney, M. (2001). Interparental conflict and family cohesion: Predictors of loneliness, social anxiety, and social avoidance in late adolescence. Fournal of Adolescent Research, 16, 304-318.

Kim, E.J., Hetherington, E.M., \& Reiss, D. (1999). Associations among family relationships, antisocial peers, and adolescents' externalizing behaviors: Gender and family type differences. Child Development, 70, 1209-1230.

Kitzmann, K.M., \& Cohen, R. (2003). Parents' versus children's perception of interparental conflict as predictors of children's friendship quality. Fournal of Social and Personal Relationships, 20, 689-700.

Kline, R.B. (2005). Principles and practice of structural equation modelling (2nd ed.). New York: The Guilford Press.

Lansford, E.J., Criss, M.M., Pettit, G.S., Dodge, KA., \& Bates, J.E. (2003). Friendship quality, and peer group affiliation, and peer antisocial behavior as moderators of the link between negative parenting and adolescent externalizing behavior. Fournal of Research on Adolescence, 13, 161-184.

Laursen, B. (1993). The perceived impact of conflict on adolescent relationships. Merrill Palmer Quarterly, 39, 535-550.

Margolin, G., Oliver, P.H., \& Medina, A.M. (2001). Conceptual issues in understanding the relation between interparental conflict and child adjustment. Integrating developmental psychopathology and risk/resilience perspectives. In Grych, J.H. \& Fincham, F.D. (Ed.), Interparental conflict and child development. Theory, research, and applications (pp. 9-38). New York, NY: Cambridge University Press.

Markiewicz, D., Doyle, A.B., \& Brendgen, M. (2001). The quality of adolescents' friendships: Associations with mothers' interpersonal relationships, attachments to parents and friends, and prosocial behaviors. Fournal of Adolescence, 24, 429-445.

Meeus, W.H.J., Akse, J., Branje, S.J.T., Ter Bogt, T., Delsing, M., Van Doorn, M.D. et al. (2001) [Codebook of the research project Conflict and Management of Relationships (CONAMORE). First and Third waves]. Unpublished manuscript, Utrecht University, The Netherlands, 2001; 2003.

Muris, P., \& Steerneman, P. (2001). The revised version of the Screen for Child Anxiety Related Emotional Disorders (SCARED-R): First evidence for its reliability and validity in a clinical sample. The British Psychological Society, 40, 35-44.

Neyer, F.J., \& Asendorpf, J.B. (2001). Personality-relationship transaction in young adulthood. Fournal of Personality and Social Psychology, 81, 1190-1204.

Raaijmakers, Q.A.W. (1999).Effectiveness of different missing data treatments in surveys with Likert-type data: Introducing the relative mean substitution approach. Educational and Psychological Measurement, 59, 725-748.

Rubin, K.H., Bukowski, W.M., \& Parker, J.G. (1998). Peer interactions, relationships, and groups. In W. Damon (Series Ed.) \& N. Eisenberg (Vol. Ed.), Handbook of child psychology, Vol. 3: Social, emotional, and personality development (5th ed.). New York: Wiley.

Shulman, S., Laursen, B., Kalman, Z., \& Karpovsky, S. (1997). Adolescent intimacy revisited. Fournal of Youth and Adolescence, 26, 597-617.

Steinberg, L., \& Silverberg, S. (1986). The vicissitudes of autonomy in early adolescence. Child Development, 57, 841-851.

Sullivan, H.S. (1953). The interpersonal theory of psychiatry. New York: W.W. Norton \& Co.

van der Valk, I. (2004). Family matters. Longitudinal studies on the associations between family structure, family process, and the adjustment of adolescents and young adolescents. Dissertation, ISED.

Wasserstein, B.S., \& La Creca, M.A. (1996). Can peer support buffer against behavioral consequences of parental discord? fournal of Clinical Child Psychology, 25, 177-182. 